\title{
Who Benefits from Altruism in Supply Chain Management?
}

\author{
Zehui Ge ${ }^{1}$, Qiying $\mathrm{Hu}^{2}$ \\ ${ }^{1}$ Business School, University of Shanghai for Science and Technology, Shanghai, China \\ ${ }^{2}$ School of Management, Fudan University, Shanghai, China \\ Email: gezehui@gmail.com,qyhu@fudan.edu.cn
}

Received September 9, 2011; revised October 12, 2011; accepted October 22, 2011

\begin{abstract}
The significant effect of social preference on strategic behavior has been convinced by recent research. Along this stream of research, we study firms' altruistic incentives in supply chains since the selfish rationality can't deal with economic behaviors. We show that the performance of the supply chain in consideration of altruism is between those of scenarios under decentralization and under integration. We further shows that a manufacturer, as a leader, should find an egoistic retailer, while a retailer, as a follower, should find a manufacturer with altruistic liability, to form a good chain.
\end{abstract}

Keywords: Supply Chain Management; Coopetition; Altruistic Preference; Advertising/Sales Effort; Pricing

\section{Introduction}

A great deal of attention has been paid to supply chain management (SCM) in the last decades, in which supply chain coordination is mainly discussed due to double marginalization in decentralized chains. However, the wholesale-price contract is commonly adopted by managers in practice, even though the literature has shown that it cannot coordinate the supply chain. Recently, some researchers try to explain this phenomenon (eg. [1]). Based on a generalized newsvendor model, this paper investigates the coexistence of competition and cooperation in a supply chain where pricing, ordering, and advertising/sales effort (henceforth ASE) are considered simultaneously. Another, we introduce social preferences into decision maker's utility to study cooperation in the supply chain.

There are three streams of research related to our paper. In the following, we briefly review the most related research and describe our contributions with respect to the vast, growing literature (See Figure 1 for a sketch).

First, the newsvendor model is the most basic model in SCM, where a retailer faces a random demand in a single period and must decide how many units of the product to stock before the demand is realized (see [2]). Reference [3] is the first to incorporate pricing into the newsvendor model by assuming that demand rate depends linearly on price. Following Whitin, the newsvendor problem has been extended by many other researchers. Reference [4] provides a significant review in the direction of research which combines pricing and inventory control. Reference [5] investigates the effects of risk aversion on the price and order quantity. Furthermore, [6] studies a joint pricing/inventory game of multiple newsvendors under competitive situations.

Besides pricing, firms often use advertising/sales effort to spur demand. This plays a key role in managing marketing-operations interface. In considering the dimension of sales effort, [7] models a simultaneous choice of sales effort and order quantities in a newsvendor environment. In considering the dimension of advertisement, there is also a huge collection of literature regarding various kinds of advertising. For instance, [8] link advertising to quantity decision in a newsvendor setting. While [9] discusses optimal pricing and advertising in a durable good duopoly, and [10] considers brand name advertising into demand identification.

The second stream related to our research is SCM with stochastic demand. Along this direction, the classic newsvendor model is also extended to include the interface (contract) of a firm with its upstream suppliers. The most prevalent contract in practice is the wholesale priceonly type, which involves the newsvendor paying a perunit wholesale price charged by the manufacturer. Reference [11] gives a complete analysis of this model under demand distributions with increasing generalized failure rate (IGFR). The wholesale-price contract does not coordinate the supply chain (see [12]), unless such social preferences as fairness are taken into consideration (e.g., [1]). 


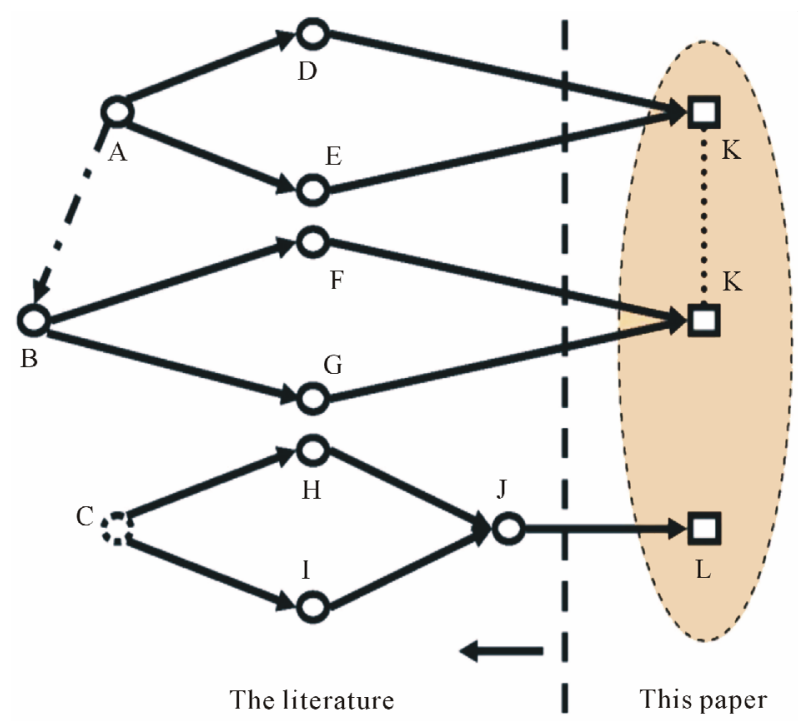

Figure 1. The position of our research. A: the classical newsvendor problem, e.g., [2]; B: a supply chain with wholesaleprice only payment, e.g., [11]; C: utility rationalizations or decision making patterns, e.g., [23]; D: ordering + pricing for a newsvendor, e.g., [4]; E: ordering + ASE for a newsvendor, e.g., $[7,8]$; F: ordering + pricing for a supply chain, e.g., [14]; G: ordering + ASE for a supply chain, e.g., [17]; H: a decentralized supply chain (competition), e.g., [13]; I: a centralized supply chain (cooperation), e.g., [23]; J: coopetition, e.g., [28]; K: ordering + pricing + ASE for a supply chain in the newsvendor setting, e.g., [22], this paper; L: coopetition in consideration of altruism, this paper.

As with the newsvendor model, other decisions are considered in SCM. By combining pricing, [13] analyzes the competition in a decentralized supply chain, and [2] presents a newsvendor pricing game in which there exist a single manufacturer and multiple retailers. Synthetically, [14] presents an extensive review of coordinated pricing and production decisions by classifying the existing models along two dimensions: deterministic versus stochastic, and static versus dynamic. Another review can be seen in [15], etc.

Nevertheless, the supply chain system can increase the total business "pie" by ASE. For instance, [16] examines coordinating contracts of a decentralized supply chain in which the retailer can choose promotional effort. For a channel rebate contract, [17] employs a simple model in which a retailer makes ordering and effort decisions and then observes demand. Furthermore, [18] investigates the impact of the retailer's sales effort on the manufacturer's sale-timing decision, in which the payment to the manufacturer depends on the retailer's order quantity. In related research, Z. Huang and his cooperators, e.g., $[19,20]$ study cooperative advertising in a supply chain with price independent/dependent demand. In the above research, the demand is deterministic. Reference [21] studies cooperative advertising model with a price dependent demand under asymmetric information structure. He et al. focus on how to coordinate a decentralized supply chain, where the retailer's sales effort, order quantity, and retail price are involved in a random demand setting ([22]). In light of the first and second streams of research, our first objective is to apply further consideration to the manufacturer's advertising efforts and focus on determining solutions for the decentralized supply chain.

The third stream related to our research entails evaluating firms' utilities in SCM. Such evaluations are related to decision-making patterns of SCM. Specifically, there are two main patterns in the current literature. One is the decentralized supply chain in which each member makes decisions to optimize its own objective. The other pattern is the centralized supply chain in which all decisions are jointly made to maximize the total profit of all members. Usually, the centralized chain is a benchmark for the decentralized one. One can see these patterns in [23], or [13].

However, firms in a chain form a relative loose vertical relationship ([24]). The supply chain may encounter a significant loss in efficiency because of the loose relationship without contractual constraints. Therefore, members in a supply chain need to coordinate their decisions to improve the chain's efficiency. In fact, seldom do successful firms in SCM take selfish actions to maximize their own profits while leaving their partners out to dry. There are plenty of studies on competitive scenarios that highlight this phenomenon, e.g., $[25,26]$.

In practice, cooperative and competitive incentives generally coexist. This phenomenon is referred to as "coopetition" ([27]). Coopetition is still an under-researched theme in SCM, even though it has been investtigated by several studies from the perspective of inventtory management. For instance, [28] develops a general framework for analyzing decentralized distribution systems with sequential decisions of inventory and allocation. In their model, ordering decisions of different retailers are assumed to be made independently/competetively, while allocation or transshipment decisions are assumed to be made cooperatively. A common focus of these studies is on firms' decision-making, but not on rationalization of firms' utilities.

On the other hand, there is sufficient evidence that firms care about their partners' profits as well as their own in order to improve the competitiveness of the total supply chain. It is well known that the chain's overall strength benefits each member. A live case comes from a global executives talk published in Harvard Business Review (see [29]) where A. B. Cummings, the president and $\mathrm{COO}$ of the Coca-Cola's Africa Group, recounts one of his successful altruistic decisions. In order to increase their bottlers' profits, Cummings increased the retail price, which resulted in increased system profitability 
after six months for both bottlers and the Coca-Cola Company itself. From a biological viewpoint, [30] conducts experiments to show how the human brain limits the impact of selfish motives and implements fair behavior. [31,32] also find that altruism is a gene-culture coevolution and an internalization of norms. In the context of SCM, [33-37] discuss the effect of altruism on strategic behavior or partnership management. Differently with these papers, we consider altruism in a generalized supply chain with such decisions as ordering, pricing and ASE. Furthermore, our findings point out who should answers more for a good vertical partnership.

Based on altruistic phenomena occurring independently of contract machines, our second objective is to study firms' behavior in a cooperative supply chain. We study coopetition in a generalized newsvendor setting, which includes three kinds of simultaneous decisions: price (both wholesale price and retail price), order quantity, and ASE. To some extent, the wholesale pricing is for competition while ASE for cooperation. At the same time, we interpret firms' cooperative incentive as their altruism, and introduce altruistic preferences to characterize firms in the supply chain. We study firms' decisions in three supply chain scenarios: integration, decentralization, and coopetition. Also, we analyze the impact of firms' altruistic preferences on performance of the supply chain through numerical analysis.

The rest of the paper is organized as follows. In Section 2 we present our model. Section 3 shows the existence of Nash equilibrium and compares three scenarios. We further present the effects of altruistic preference on decision-making by numerical analysis in Section 4. Finally, Section 5 concludes this paper.

\section{Model}

The supply chain considered here consists of one retailer and one manufacturer. As usual in the literature, the manufacturer (denoted by $\mathrm{M}$ ) acts as a leader, and the retailer (denoted by $\mathrm{R}$ ) follows. For a type of product supplied, the manufacturer firstly offers a wholesale price $w$ and a brand name advertising level $a_{m}$. As a response, the retailer orders $q$ units and retails them at price $p$ per unit. At the same time, he decides his sales effort level $a_{r}$. The stochastic demand faced by the retailer depends on $a_{m}, a_{r}$, and $p$. Unmet demand is lost. The unit producing cost is $c_{m}$, and the retailing one is $c_{r}$. It is convenient to assume that the unit costs $C_{m}$ and $c_{r}$ are constants, since our purpose is to examine basic properties of altruism in SCM.

The demand is as follows,

$$
D=d\left(p, a_{m}, a_{r}\right)+\theta=\gamma(p) a_{m}^{s} a_{r}^{t}+\theta .
$$

Here $d\left(p, a_{m}, a_{r}\right)$ is the deterministic portion, where $\gamma(p)$ is a base price-demand function, $s>0$ indicates the effort effectiveness associated with the brand name advertising, and $t>0$ with local sales effort. Moreover, $a_{m}^{s} a_{r}^{t}$ is assumed to be concave in both $a_{m}$ and $a_{r}$, which implies that (the deterministic portion of) the demand increases with both types of effort, but at a diminishing rate. $\theta$ in Equation (1) is a random variable in $[A, B] \subset(0, \infty)$ with the probability density function $f(\cdot)$ and cumulative distribution function $F(\cdot)$.

Let $\tau=q-d\left(p, a_{m}, a_{r}\right)$ represent a stocking factor, which describes the gap between the order quantity and the deterministic portion of the demand. After the random part of the demand is realized, if it exceeds $\tau$, we say there occurs stocking shortage, otherwise, stocking residue. The expected sale quantity of the retailer is

$$
\begin{aligned}
E \min \{q, D\} & =q-\int_{A}^{\tau} F(\theta) \mathrm{d} \theta \\
& =\gamma(p) a_{m}^{s} a_{r}^{t}+\tau-\int_{A}^{\tau} F(\theta) \mathrm{d} \theta .
\end{aligned}
$$

Therefore, the retailer's expected profit is

$$
\begin{aligned}
\pi_{r}\left(w, p, q, a_{m}, a_{r}\right) & =p E \min \{q, D\}-\left(w+c_{r}\right) q-a_{r} \\
& =\left(p-w-c_{r}\right) q-p \int_{A}^{\tau} F(x) \mathrm{d} x-a_{r},
\end{aligned}
$$

and the profit of the manufacturer is

$$
\pi_{m}\left(w, a_{m}, q\right)=\left(w-c_{m}\right) q-a_{m} .
$$

The total profit of the supply chain, defined as the sum of those of the manufacturer and the retailer, is

$$
\begin{aligned}
& \pi_{s}\left(p, q, a_{m}, a_{r}\right) \\
& =\pi_{m}\left(w, a_{m}, q\right)+\pi_{r}\left(w, a_{m}, q, p, a_{r}\right) \\
& =\left(p-c_{m}-c_{r}\right) q-p \int_{A}^{\tau} F(x) \mathrm{d} x-a_{m}-a_{r} .
\end{aligned}
$$

For convenience, we abbreviate their profits as $\pi_{r}$, $\pi_{m}, \pi_{s}$, respectively.

Without loss of generality, we assume $p$ ranges from $c_{m}+c_{r}$ to an upper bound $p$. Obviously, the retailer will set $p>w+c_{r}$ so as to get a positive profit. The following proposition presents the scope of the stocking factor $\tau$.

Proposition 1 The stocking factor $\tau$ always falls into the support set of $\varepsilon$, i.e., $[A, B]$.

All the proofs see Appendix. Now, we make the following assumption for our model.

Assumption $1 \gamma(p)$ is twice differentiable, and satisfies: 1) $\gamma(p)>0$ and $\gamma^{\prime}(p)>0$, and 2)

$2 \gamma^{\prime}(p)^{2}-\gamma(p) \gamma^{\prime \prime}(p)>0$.

The twice differentiability above is merely for convenience, for it simplifies our description. Item 1) above indicates that the retailer faces a downward sloping and nonnegative base demand curve. Item 2) above is ensured by the concavity of $\gamma(p)$. Since it can be written as $\gamma^{\prime \prime}(p)<2 \gamma^{\prime}(p)^{2} / \gamma(p)$ when the demand is convex, 
it indicates that the degree of convexity is not too large for any given $p$. Certainly, it holds when the demand is concave. By examination, we find that Assumption 1 is true for most demand functions (e.g., exponential demand $\gamma(p)=e^{-\beta p}$ and linear demand $\gamma(p)=\alpha-\beta p$ for $\beta>0$, power demand $\gamma(p)=p^{-\beta}$ with $\left.\beta>1\right)$.

\subsection{Integrated Supply Chain}

For the integrated supply chain (IS), both the manufacturer and the retailer belong to the same enterprise with the total profit $\pi_{s}$. Thus, the problem is to maximize $\pi_{s}$ by choosing $a_{m}, q, p$ and $a_{r}$ :

$$
\max _{a_{m}, q, p, a_{r}} \pi_{s}=\left(p-c_{m}-c_{r}\right) q-p \int_{A}^{\tau} F(x) \mathrm{d} x-a_{m}-a_{r} .
$$

For uniform symbol definition, $\pi_{s}$ will be rewritten as $U_{s}$ in the remainder.

\subsection{Decentralized Supply Chain}

In the decentralized supply chain (DS) the manufacturer, as a leader, chooses her wholesale price $w$ and brand name advertising level $a_{m}$. Then the retailer chooses the order quantity $q$, sales effort level $a_{r}$, and retailing price $p$ as his response. They both want to maximize her/his own expected profit by playing a Stackelberg game as follows,

$$
\begin{aligned}
& \text { Stage 1: } \max _{w, a_{m}} \pi_{m}, \\
& \text { Stage 2: } \max _{p, q, a_{r}} \pi_{r} .
\end{aligned}
$$

This will be solved by the backward method in the next section.

\subsection{Coopetitive Supply Chain}

In the literature of SCM, it is assumed that all members in the supply chain exclusively pursue their own profits and do not care about "social" goals per se. As we have explained in the Introduction, firms may care about others' profits in order to enhance the system's competetiveness. Certainly, they still pursue their own profits at the same time. That is, they may be both egoistic and altruistic. When making decisions, each firm may trade off its own profit together with their partner's profit. For this, we introduce altruistic preferences $\eta_{m}$ and $\eta_{r}$ for the manufacturer and the retailer, respectively.

In this paper, we model altruistic preferences in firms' utilities by adopting a weighted summing formulation. This mean the utilities of the manufacturer and the retailer are, respectively,

$$
\begin{aligned}
& U_{m}=\pi_{m}+\eta_{m} \pi_{r}, \\
& U_{r}=\pi_{r}+\eta_{r} \pi_{m} .
\end{aligned}
$$

It is assumed that both $\eta_{m}$ and $\eta_{r}$ belong to $[0,1)$, since firms reasonably care about their own profits more than that of others. The larger the altruistic preference, the more altruistic the firm will be.

The decision mechanism here is exactly as that in the scenario (DS). That is, first the manufacturer chooses $w$ and $a_{m}$, and then the retailer decides $p, q$, and $a_{r}$. Hence, the coopetition of the supply chain (denoted by $\mathrm{CS}$ ) can be formulated as

$$
\begin{aligned}
& \text { Stage 1: } \max _{w, a_{m}} U_{m} \\
& \text { Stage 2: } \max _{p, q, a_{r}} U_{r}
\end{aligned}
$$

Clearly, (DS) is a special case of (CS).

We use superscripts D, C, and I to designate three scenarios in this paper, (DS), (CS) and (IS), respectively.

\section{Remark 1}

1) Another interpretation of Equation (5) is that each firm wants to maximize the weighted sum of his/her own profit and the chain's profit. Then, the utility of the manufacturer is $\alpha \pi_{m}+(1-\alpha)\left(\pi_{m}+\pi_{r}\right)=\pi_{m}+(1-\alpha) \pi_{r}$ for any given parameter $\alpha$, which means $\eta_{m}=(1-\alpha)$. The same with the retailer.

2) It should be noted that $U_{m}=U_{s}=U_{r}$ when both $\eta_{m}$ and $\eta_{r}$ approach to 1 , but (CS) here is not the integrated scenario, since (CS) is still a decentralized system with the manufacturer and the retailer as its two decision makers. However, this should be studied using a different method. Hence, we do not give much attention to it in this paper.

\section{Nash Equilibrium}

In this section, we solve the three scenarios. Before doing this, we first make some preparations.

\subsection{Some Preparations}

We will introduce two functions $\varphi_{w}(p)$ and $M_{w}(p)$ in this subsection. For the first function $\varphi_{w}(p)$, we consider a basic decentralized setting where

1) both effort levels $a_{m}$ and $a_{r}$ are exogenous, i.e., constant; and

2) the demand is deterministic, i.e., $\theta=0$.

So we can assume that the demand is

$D=d(p)=\gamma(p)$. This basic setting will be used to compare our results with those in the literature.

Since the supply chain is decentralized, we can get the following result when $q>\gamma(p)$ (it is essential to assume $a_{m}=a_{r}=1$ )

$$
\begin{aligned}
\pi_{r}(w, p, q, 1,1) & =p E \min \{q, \gamma(p)\}-\left(w+c_{r}\right) q \\
& =\left(p-w-c_{r}\right) \gamma(p)-\left(w+c_{r}\right)[q-\gamma(p)] \\
& <\left(p-w-c_{r}\right) \gamma(p)=\pi_{r}(w, p, \gamma(p), 1,1) .
\end{aligned}
$$

Similarly, we still have the same result when 
$q<\gamma(p)$. Therefore, it is optimal for the retailer to order $q=\gamma(p)$ for any given $w$ and $p$. Then the retailer's profit (denoted by $\varphi(p)$ ) in the basic decentralized setting is

$$
\begin{aligned}
\varphi_{w}(p) & =\pi_{r}(w, p, \gamma(p)) \\
& =\left(p-w-c_{r}\right) \gamma(p), \\
p & >w+c_{r} .
\end{aligned}
$$

The following proposition shows the existence and uniqueness of the optimal retail price in this basic setting.

Proposition 2 There exists a unique optimal retail price $p_{w}^{*}$ at which $\varphi_{w}(p)$ is maximized.

The second function is defined by

$$
\begin{aligned}
M_{w}(p)= & A+\int_{A}^{F^{-1}\left[\left(p-w-c_{r}\right) / p\right]} \bar{F}(\theta) \mathrm{d} \theta \\
& + \begin{cases}\kappa^{1} \varphi_{w}(p)^{\frac{t+s}{1-t-s}} \varphi_{w}^{\prime}(p), & w=c_{m}, \\
\kappa^{2} a_{m}^{\frac{s}{1-t}} \varphi_{w}\left((p)^{\frac{t}{1-t}} \varphi_{w}^{\prime}(p)\right. & w>c_{m}\end{cases}
\end{aligned}
$$

for any $w \geq c_{m}$, where $\kappa^{1}=\left(s^{s} t^{t}\right)^{\frac{1}{1-t-s}}$ and $\kappa^{2}=t^{\frac{t}{1-t}}$ are two constants determined by $s$ and $t$, and

$\bar{F}(\cdot)=1-F(\cdot)$. The meaning of $M_{w}(p)$ will be given in the following subsection. Here, we get one proposition from the continuity of $M_{w}(p)$.

Proposition 3 There must exist a price $p_{w}^{* *}$ minimizing $M_{w}(p)$ in $\left[c_{m}+c_{r}, \bar{p}\right]$.

The minimum of $M_{w}(p)$, i.e., $M_{w}\left(p_{w}^{* *}\right)$, will be used to judge whether the Nash equilibrium exists in the following subsections.

\subsection{Optimal Solutions of (IS)}

In this subsection, we get optimal solutions for scenario (IS). Its first-order condition is obviously as follows,

$$
\left\{\begin{array}{l}
\partial U_{s} / \partial p=q+p \gamma^{\prime}(p) a_{m}^{s} a_{r}^{t} F(\tau)-\int_{A}^{\tau} F(\theta) \mathrm{d} \theta=0 \\
\partial U_{s} / \partial q=p \bar{F}(\tau)-c_{m}-c_{r}=0 \\
\partial U_{s} / \partial a_{m}=\operatorname{sp} \gamma(p) a_{m}^{s-1} a_{r}^{t} F(\tau)-1=0 \\
\partial U_{s} / \partial a_{r}=\operatorname{tp} \gamma(p) a_{m}^{s} a_{r}^{t-1} F(\tau)-1=0
\end{array}\right.
$$

By using some mathematic technologies we can get $a_{m}, a_{r}$, and $q$, as functions of $p$ as follows.

$$
\left\{\begin{array}{l}
a_{r}^{1-t-s}=s^{s} t^{1-s} \varphi_{c_{m}}(p) \\
a_{m}=\kappa^{1} \varphi_{c_{m}}(p)^{\frac{1}{1-t-s}} \\
q=\kappa^{1} \gamma(p) \varphi_{c_{m}}(p)^{\frac{t+s}{1-t-s}}+F^{-1}\left[\left(p-w-c_{r}\right) / p\right]
\end{array}\right.
$$

We write as $a_{m}(p), a_{r}(p)$, and $q(p)$ when necessary. Substituting the above three equations into the first equation in (8) and rearranging it, we get the fol- lowing condition that an optimal price must satisfy:

$$
\begin{aligned}
0= & q+p \gamma^{\prime}(p) a_{m}^{s} a_{r}^{t} F(\tau)-\int_{A}^{\tau} F(\theta) \mathrm{d} \theta \\
= & \kappa^{1} \varphi_{c_{m}}(p)^{\frac{t+s}{1-t-s}}\left[\gamma(p)+\gamma^{\prime}(p)\left(p-c_{m}-c_{r}\right)\right] \\
& +\int_{A}^{F^{-1}\left[\left(p-c_{m}-c_{r}\right) / p\right]} \bar{F}(\theta) \mathrm{d} \theta+A \\
= & \kappa^{1} \varphi_{c_{m}}(p)^{\frac{t+s}{1-t-s}} \varphi_{c_{m}}^{\prime}(p)+\int_{A}^{F^{-1}\left[\left(p-c_{m}-c_{r}\right) / p\right]} \bar{F}(\theta) \mathrm{d} \theta+A \\
= & M_{c_{m}}(p) .
\end{aligned}
$$

Hence, the solution of Equation (8) can be found by solving Equation (10), which includes only one variable $p$. Actually, $M_{c_{m}}(p)$ represents the marginal profit of the integrated supply chain on the retail price whenever the other decision variables change with $p$ according to (9). Hereafter, we call $M_{c_{m}}(p)$ an augmented marginal profit of (IS). This shows the following theorem.

Theorem 1 Under optimality for (IS), the optimal retail price satisfies $M_{c_{m}}(p)=0$, and $a_{m}, a_{r}$, and $q$ are determined by Equation (9).

From the theorem above we know decision-making in (IS) can be realized by solving $M_{c_{m}}(p)=0$. Thus, it is important to judge the sign of $M_{c_{m}}(p)$ for any given $p$. Now we further discuss some properties of $M_{c_{m}}(p)$.

Lemma $11 M_{c_{m}}(p)>0$ for all $p \in\left[c_{m}+c_{r}, p_{c_{m}}^{*}\right]$, and $p_{c_{m}}^{* *}>p_{c_{m}}^{*}$ whenever $M_{c_{m}}\left(p_{c_{m}}^{* *}\right) \leq 0$.

Remembering that $p_{c_{m}}^{*}$ is the retailer's optimal price in the basic decentralized setting, Lemma 1 establishes a comparison of $p_{c_{m}}^{*}$ with the minimizer of $M_{c_{m}}(p)$. When the augmented marginal profit in (IS) is non-positive, i.e., $M_{c_{m}}(p) \leq 0$, the supply chain has no incentive to further increase the retail price. In fact the chain will drop the retail price in order to increase its profit. Then, the optimal retail price (denoted by $p^{I}$ ) in (IS) should be larger than the basic decentralized pricing $p_{c_{m}}^{*}$, as shown in the following theorem, where the existence of the optimal solution for (IS) is proved. In the theorem, we denote by $N(p)=\left(p, q(p), a_{m}(p), a_{r}(p)\right)$ the solution induced by the retail price $p$ for (IS) via Equation (9).

Theorem 2 For (IS), there must exist an optimal solution $\left(p^{I}, q^{I}, a_{m}^{I}, a_{r}^{I}\right)$. Moreover,

1) if $M_{c_{m}}\left(p_{c_{m}}^{* *}\right)<0$ then there is an interior solution $p^{I} \in\left(p_{c_{m}}^{*}, p_{c_{m}}^{* *}\right)$ satisfying

$$
M_{c_{m}}\left(p_{c_{m}}^{I}\right)=0, M_{c_{m}}^{\prime}\left(p_{c_{m}}^{I}\right) \leq 0 .
$$

Furthermore, for any $p^{I} \in\left(c_{m}+c_{r}, \bar{p}\right)$ satisfying Equation (11), $N\left(p^{I}\right)$ must be a local optimal solution of (IS);

2) If $M_{c_{m}}\left(p_{c_{m}}^{* *}\right)>0$, the optimal solution is $N(\bar{p})$;

3) If $M_{c_{m}}\left(p_{c_{m}}^{* *}\right)=0$, the optimal solution is either 
$N\left(p_{c_{m}}^{* *}\right)$ or $N(\bar{p})$.

We make no direct restriction on the distribution function $F(\cdot)$, though it may influence $M_{c_{m}}\left(p_{c_{m}}^{* *}\right)$. One of our important results is that the optimal retail price in (IS) is larger than the one obtained in the basic decentralized setting; i.e., $p^{I}>p_{c_{m}}^{*}$. This result comes from our incorporating with uncertainty demand and ASE, since the retailer sets a higher price so as to mitigate the effects of uncertainty and promoting effort.

The second result in Theorem 2 refers to such a nonnormal market in which the augmented marginal profit is always positive, no matter how high the retailing price is. In this type of market, the retailer will set $p$ to be the upper bound $\bar{p}$. When $\bar{p}$ is sufficiently large, it is obvious that $N(\bar{p})=(\bar{p}, B, 0,0)$ in this time. That is, the retailer will order a quantity of $B$, and the deterministic part of the demand approaches to zero, all $B$ units are stocked only for matching the stochastic part of the demand. Furthermore, both manufacturer and retailer need no advertising/sales efforts. Such a case is the contingent market, where almost all inventories meet emergencies, and then retailers are inclined to bid up price. Therefore, this type of market would be better to be supervised by the government (e.g., a market of such products against food crisis).

From the proof of Theorem 2 we know that if $M_{c_{m}}(\bar{p})<0$ then $\bar{p}$ would not be optimal. This shows the following corollary.

Corollary 1 If $M_{c_{\mathrm{m}}}(\bar{p})<0$ and Equation (11) has a unique interior solution $p^{I} \in\left(c_{m}+c_{r}, \bar{p}\right)$, then $N\left(p^{I}\right)$ is the unique optimal solution of (IS).

Moreover, we present a sufficient condition to ensure the uniqueness of solutions for Equation (11).

Proposition 4 If $M_{c_{m}}(p)<0$ is downwards unimodal, Equation (11) has a unique solution in $\left[c_{m}+c_{r}, \bar{p}\right]$.

The proof of the proposition is obvious.

Remark 2 A given function is downwards (upwards) unimodal in an interval $[a, b]$, if and only if it has the unique minimal (maximal) point $x^{*}$ and is monotone on either side of $x^{*}$ in the interval (see e.g., [38]). In the following two special cases, the downwards unimodality of $M_{c_{m}}(p)$ is clear.

1) The stochastic portion $\theta$ in the demand follows a uniform distribution on $[A, B]$.

2) The deterministic demand is linear in $p$, i.e., $\gamma(p)=Q-k p$, where $Q$ and $k$ are constants and $p \in\left[c_{m}+c_{r}, Q / k\right]$. In fact, one can examine that $M_{c_{m}}^{\prime \prime}(p)$ is increasing in $p \in\left[c_{m}+c_{r}, Q / k\right]$ when $t+s=0.5$. Then, it is easy to conclude that $M_{c_{m}}(p)$ is downwards unimodal.

\subsection{Nash Equilibriums of (CS)}

First we consider the retailer's response provided with $w$ and $a_{m}$ of the manufacturer.

The first-order condition for the retailer is

$$
\left\{\begin{array}{l}
\partial U_{s} / \partial p=q+p \gamma^{\prime}(p) a_{m}^{s} a_{r}^{t} F(\tau)-\int_{A}^{\tau} F(\theta) \mathrm{d} \theta=0, \\
\partial U_{s} / \partial q=p \bar{F}(\tau)-w-c_{r}+\eta_{r}\left(w-c_{m}\right)=0 \\
\partial U_{s} / \partial a_{r}=t p \gamma(p) a_{m}^{s} a_{r}^{t-1} F(\tau)-1=0 .
\end{array}\right.
$$

Similar to (9), we get

$$
\left\{\begin{array}{l}
a_{r}^{1-t}=t a_{m}^{s} \varphi_{\bar{w}}(p) \\
q=\kappa^{2} a_{m}^{\frac{s}{1-t}} \gamma(p) \varphi_{\bar{w}}(p)^{\frac{t}{1-t}}+F^{-1}\left[\left(p-\bar{w}-c_{r}\right) / p\right]
\end{array}\right.
$$

where $\bar{w}=w-\eta_{r}\left(w-c_{m}\right)$. Substituting (13) into the first equation in (12), we obtain

$$
\begin{aligned}
& \kappa^{2} a_{m}^{\frac{s}{1-t}} \varphi_{\bar{w}}(p)^{\frac{t}{1-t}} \varphi_{\bar{w}}^{\prime}(p)+\int_{A}^{F^{-1}\left[\left(p-\bar{w}-c_{r}\right) / p\right]} \bar{F}(\theta) \mathrm{d} \theta+A \\
& =M_{\bar{w}}(p)=0 .
\end{aligned}
$$

There exist solutions of Equation set (12) as long as Equation (14) has roots. Thus, the existence of an optimal response from the retailer can be obtained by solving $M_{\bar{w}}(p)=0$. Then, similar to Theorem 2, we have the following result about the retailer's optimal response in the scenario (CS). Here, we denote by $N R(p)=(p, q(p)$, $\left.a_{m}(p), a_{r}(p)\right)$ the solution of the retailer induced from $p$.

Theorem 3 There must exist an optimal response $\left(p\left(w, a_{m}\right), q\left(w, a_{m}\right), a_{r}\left(w, a_{m}\right)\right)$ for the retailer in (CS), provided with $w>c_{m}$ and $a_{m}>0$. Moreover,

1) if $M_{\bar{w}}\left(p_{\bar{w}}^{* *}\right)<0$ then there is an interior solution $p^{C} \in\left(p_{\bar{w}}^{*}+c_{r}, p_{\bar{w}}^{* *}\right)$ satisfying

$$
M_{\overline{\mathrm{w}}}\left(p^{C}\right)=0, M_{\overline{\mathrm{w}}}\left(p^{C}\right) \leq 0 .
$$

Furthermore $N R\left(p^{C}\right)$ must be a local optimal response of the retailer;

2) If $M_{\bar{w}}\left(p_{\bar{w}}^{* *}\right)>0$ then the retailer's optimal response is either $N R(\bar{p})$ or $N R\left(\bar{w}+c_{r}\right)$;

3) If $M_{\bar{w}}\left(p_{\bar{w}}^{* *}\right)=0$ then the retailer's optimal response is $N R\left(p_{\bar{w}}^{* *}\right), N R\left(\bar{w}+c_{r}\right)$, or $N R(\bar{p})$.

Theorem 3 gives the retailer's optimal response to the manufacturer. Thus $p, q$, and $a_{r}$ are functions of $w$ and $a_{m}$, respectively. A sufficient condition to guarantee the uniqueness of these response functions is that $M_{\bar{w}}(p)$ is unimodal. Substituting the functions into the manufacturer's utility yields

$$
\begin{aligned}
U_{m}\left(w, a_{m}\right) & =U_{m}\left(w, a_{m}, q\left(w, a_{m}\right), p\left(w, a_{m}\right), a_{r}\left(w, a_{m}\right)\right) \\
& =\pi_{m}\left(w, a_{m}\right)+\eta_{m} \pi_{r}\left(w, a_{m}\right),
\end{aligned}
$$

The first-order condition for the manufacturer is 


$$
\left\{\begin{array}{l}
\left(1-\eta_{m} \eta_{r}\right)\left(w-c_{m}\right) \partial q / \partial w+\left(1-\eta_{m}\right) q=0, \\
\left(1-\eta_{m} \eta_{r}\right)\left(w-c_{m}\right) \partial q / \partial a_{m}-1+\eta_{m} s a_{r} /\left(t a_{m}\right)=0 .
\end{array}\right.
$$

Therefore, we can obtain the manufacturer's best response according to Equation (16).

\subsection{Comparison of Scenarios}

In this subsection, we compare retailer's order quantities given the three scenarios. Denote the solutions in (DS), (CS), (IS), as $\left(w^{D}, a_{m}^{D}, p^{D}, q^{D}, a_{r}^{D}\right),\left(w^{C}, a_{m}^{C}, p^{C}, q^{C}, a_{r}^{C}\right)$, and $\left(w^{I}, a_{m}^{I}, p^{I}, q^{I}, a_{r}^{I}\right)$, respectively. The following theorem compares the order quantities.

Theorem 4 For the order quantities in the three scenarios, we have $q^{I} \geq q^{C} \geq q^{D}$.

From the theorem above, cooperative incentives increase the retailer's order quantity (vs. scenario (DS)). On the other hand, the order quantity in (CS) may be lower than that in (IS) because of the existence of the competitive incentives. Thus, the coexistence of competition and cooperation makes firms' decisions inconsistent with those in (IS) or (DS), just between those of (IS) and (DS).

\subsection{Effects of the Altruistic Preferences on Decisions and Profits}

This section gives some meaningful observations by analyzing numerical results. Especially, we focus on the effects of the altruistic preferences on decisions and profits in (CS) (certainly, including (DS) as a special case). We assume the base price-demand function $\gamma(p)$ to be linear, that is, $\gamma(p)=Q-k p$ for some positive constants $Q$ and $k$. Surely, the domain of the retail price is $0 \leq p \leq Q / k$. Furthermore, it is assumed that $\theta$ follows an exponential distribution with rate of $\lambda$, i.e. $f(\theta)=\lambda e^{-\lambda \theta}$ when $\theta \geq 0$; otherwise $f(\theta)=0$. Let $c_{m}=2, \quad c_{r}=1, \lambda=1, Q=15, k=1$.

Table 1 gives some numerical results under $s=0.15$, $t=0.1$, in which the values of (DS) corresponds to a classical scenario presented in the previous literature in Figure 1. By comparing the Nash equilibria and profits for (IS), (DS), and (CS) given in the table, we find a reasonable explanation why decisions diverge in reality, which is just our main contribution. Moreover, we get the following interesting observations different with those in the current literature.

Observation 1 Among three scenarios, (IS) has the highest chain's profit, order quantity, advertising, sales effort level, and the lowest retail price; Conversely, (DS) has the lowest chain's profit, order quantity, advertising, sales effort level, and the highest retail price; And (CS) is between (IS) and (DS).

We have shown in Theorem 4 that the order quantity under (CS) is between those of (IS) and (DS). Now, the
Table 1. Nash equilibria and profits when $s=0.15, t=0.1$.

\begin{tabular}{cccccc}
\hline $\mathrm{S}$ & $\eta_{m}$ & $\eta_{r}$ & $w$ & $p$ & $q$ \\
\hline$(\mathrm{IS})$ & - & - & - & 9.202 & 10.756 \\
$(\mathrm{DS})$ & 0 & 0 & 7.349 & 11.790 & 4.386 \\
$(\mathrm{CS})$ & $3 / 7$ & 0 & 5.744 & 11.011 & 6.043 \\
$(\mathrm{CS})$ & 0 & $1 / 4$ & 9.137 & 11.785 & 4.626 \\
$(\mathrm{CS})$ & $2 / 3$ & $1 / 4$ & 5.822 & 10.583 & 7.172 \\
\hline $\mathrm{S}$ & $a_{m}$ & $a_{r}$ & $\pi_{m}$ & $\pi_{r}$ & $\pi_{s}$ \\
\hline (IS) & 8.967 & 5.974 & - & - & 47.648 \\
$(\mathrm{DS})$ & 3.727 & 1.391 & 19.734 & 13.076 & 32.810 \\
$(\mathrm{CS})$ & 5.103 & 2.369 & 17.522 & 22.284 & 39.806 \\
$(\mathrm{CS})$ & 5.229 & 1.469 & 27.789 & 5.531 & 33.320 \\
$(\mathrm{CS})$ & 6.710 & 3.105 & 20.700 & 22.342 & 43.042 \\
\hline
\end{tabular}

observation above further illustrates not only this fact, but also all the other decisions and profits of the chain.

Figures 2-5 and Figures 6-9 show changes of decisions and profits, respectively, with the altruistic preferences. From Figures 2, 3, and 6, 7, we find that for any given $\eta_{m}$, there is a switching level, denoted by $\eta_{r}^{*}$ for the retailer, such that when $\eta_{r} \geq \eta_{r}^{*}$ is large enough, an altruistic retailer sets his optimal price as low as possible, that is, $p^{C}=w^{C}+c_{r}$ under the constraint $p \geq w^{C}+c_{r}$. As a follower in the game, the retailer in this circumstance benefits nothing from the selling, but has to suffer from the effort and demand uncertainty, and thus has a negative profit, due to being too altruistic. Similarly, from Figures 8 and 9, the manufacturer has negative profit if she is very altruistic $\left(\eta_{m} \geq \eta_{m}^{*}\right.$ for some $\eta_{m}^{*}$, which is near 1). We call this phenomenon "doing for others". Moreover, the switching level for the manufacturer is higher than that for the retailer, which implies that the retailer is more likely to suffer from being too altruistic than the manufacturer. This may be due to the manufacturer's first-mover advantage.

From the switching level in Figure 3, we know that as retailer's altruistic preference $\eta_{r} \in\left[0, \eta_{r}^{*}\right]$ increases, so does the wholesale price $w$ and the retail price $p$, causing demand to decrease along with the retailer's order quantity $q$ and effort $a_{r}$. But when the retailer is too altruistic with $\eta_{r} \geq \eta_{r}^{*}$, he is "doing for others". So, both $w$ and $p$ decrease, and the demand increases along with $q$ and $a_{r}$. This switching becomes more serious as the manufacturer's altruistic preference $\eta_{m}$ increases. In fact, when $\eta_{m}=0, q$ and $a_{r}$ increase a little in $\eta_{r} \leq \eta_{r}^{*}$ (Figure 2).

On the other hand, it can be seen from Figures $\mathbf{4}$ and $\mathbf{5}$ that the effect of the manufacturer's $\eta_{m}$ on decisions is 
when $\eta_{m}=0.0101$

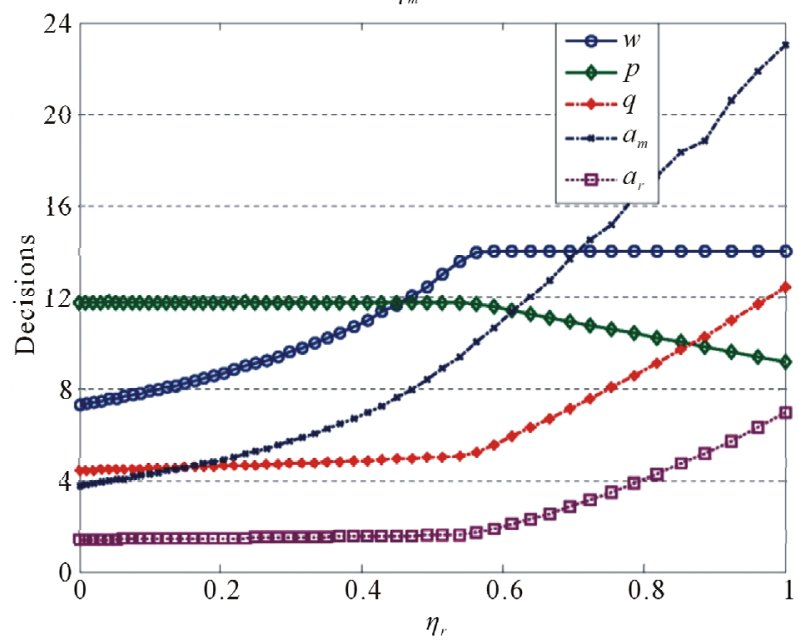

Figure 2. Decision shift with $\eta_{r}$.

when $\eta_{m}=0.8182$

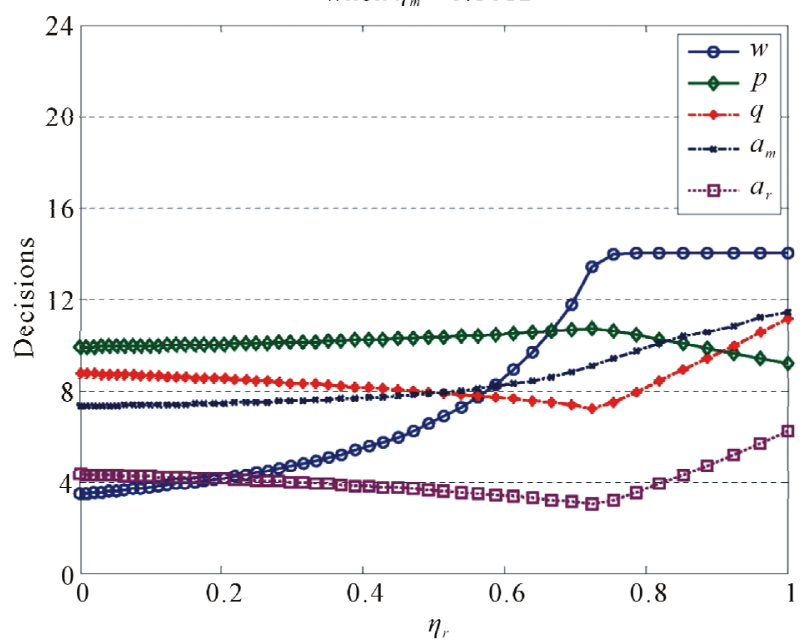

Figure 3. Decision shift with $\eta_{r}$.

when $\eta=0.0101$

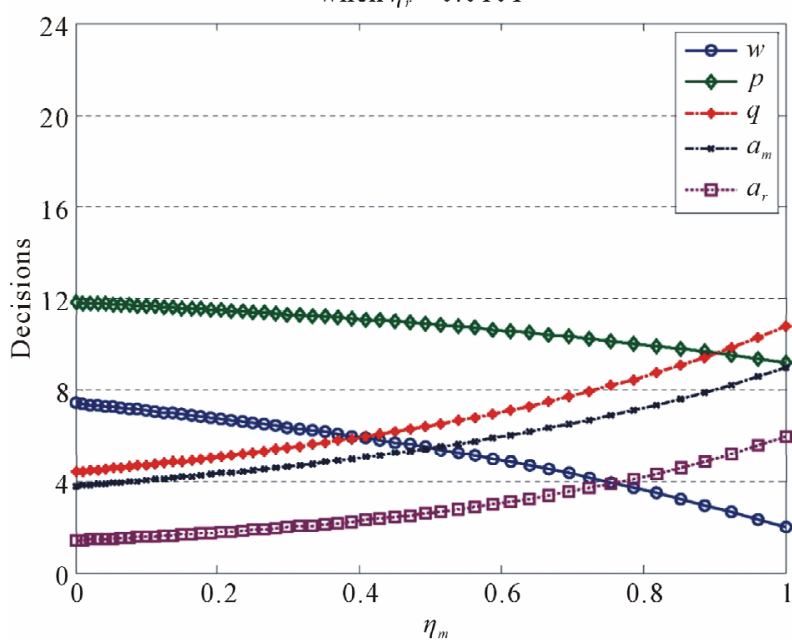

Figure 4. Decision shift with $\eta_{m}$.

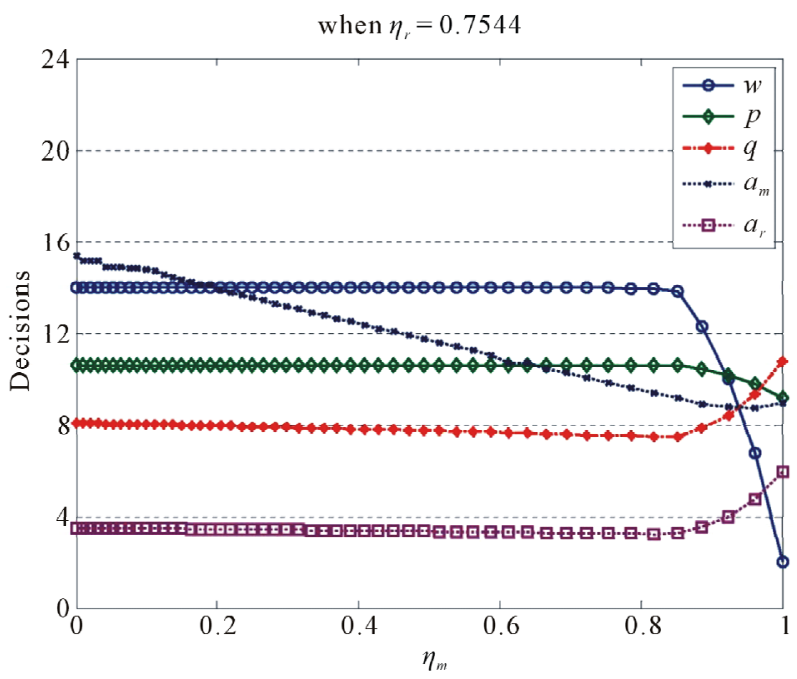

Figure 5. Decision shift with $\eta_{m}$.

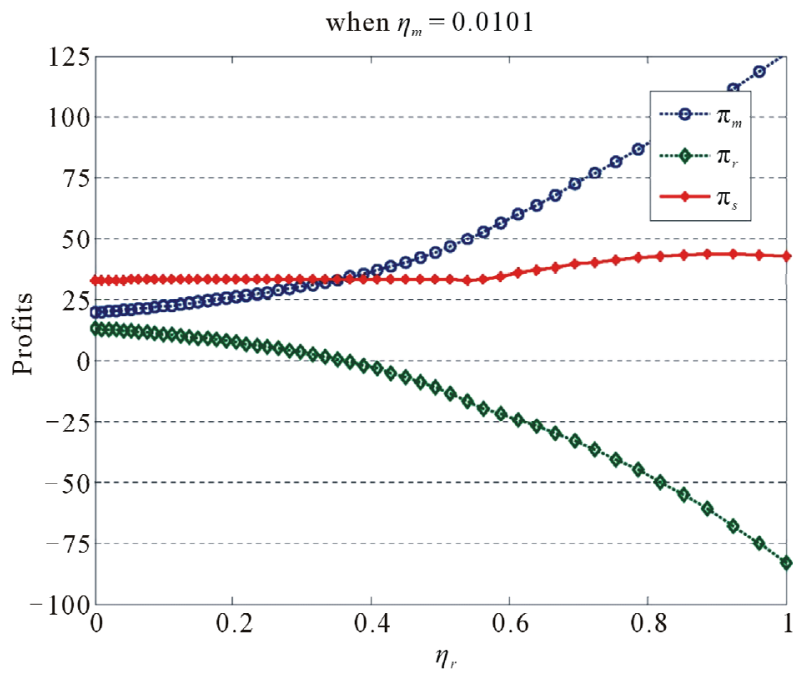

Figure 6. Profit shift with $\eta_{r}$.

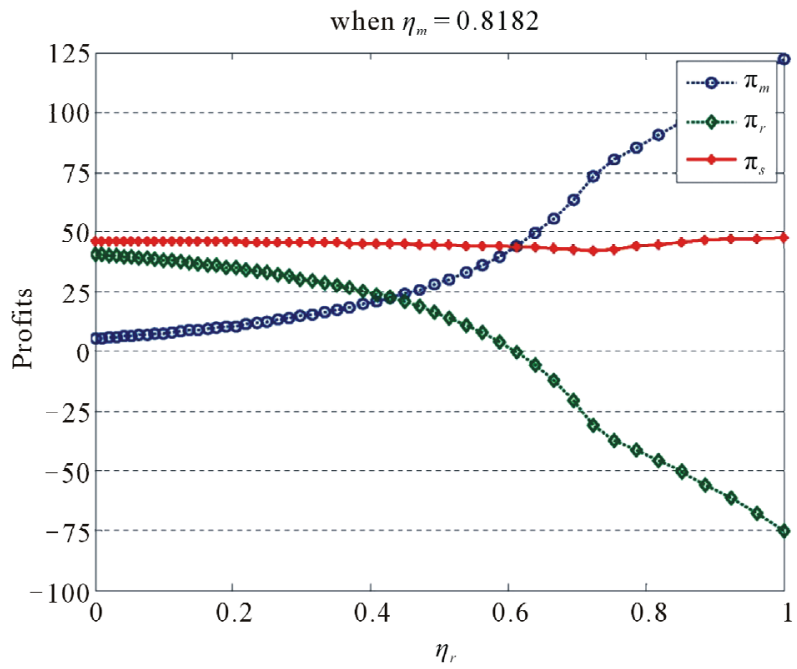

Figure 7. Profit shift with $\eta_{r}$. 


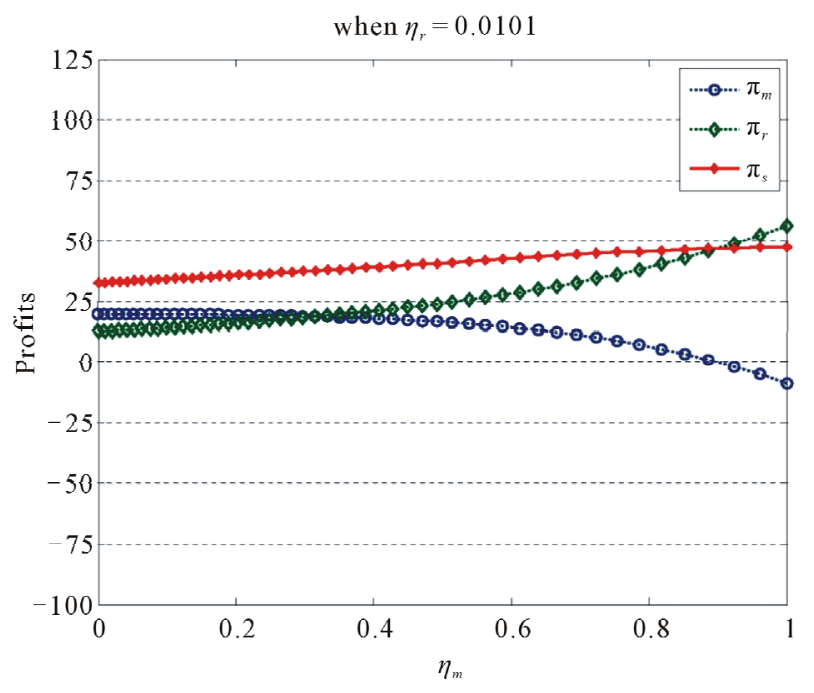

Figure 8. Profit shift with $\eta_{r}$.

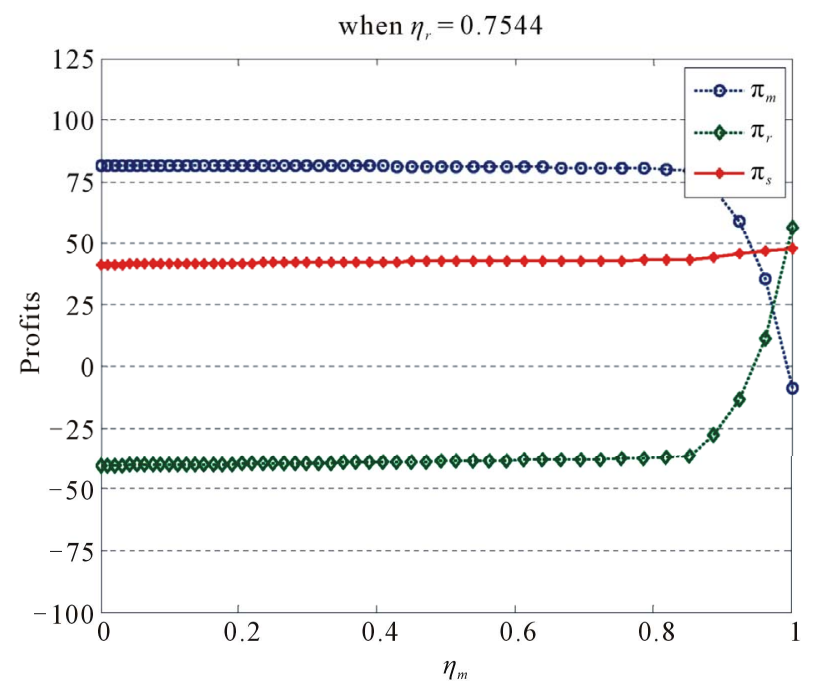

Figure 9. Profit shift with $\eta_{r}$.

very regular and simple: with increase of $\eta_{m}$, both prices $w$ and $p$ decrease while other decisions $q, a_{r}$, and $a_{m}$ increase. This surely benefits the supply chain (see Figures 8 and 9).

Among all decisions, the retail price $p$ is the weakest one affected by altruistic preferences, while the wholesale price $w$ is the most seriously affected. One possible interpretation of this is that the retail price is mainly determined by the market, other than by type of supply chain, while $w$ directly reflects the profit allocation between the retailer and the manufacturer.

By comparing Figures 2 and $\mathbf{3}$ with Figures $\mathbf{4}$ and $\mathbf{5}$, we find that an altruistic manufacturer will lead to high $\left(q^{C}, a_{m}^{C}, a_{r}^{C}\right)$, and low $w^{C}$, and also to high profits for the retailer and the supply chain. As for the type of retailer, its influence is not serious.

In the following, we focus our attention on how the al- truistic preferences affect the profits of the manufacturer, the retailer, and the system. In general, firms are willing to benefit their partner only when they face positive profits. Then, our analysis in the following focuses on the normal circumstance in which both firms have positive profits and so have incentives to participate (especially, $\eta_{m} \leq \eta_{m}^{*}$ and $\eta_{r} \leq \eta_{r}^{*}$ ). However, firms should not be too altruistic, i.e., their altruistic preferences should not be too great. Hence, it is reasonable to limit our discussion below in $\eta_{m} \leq \eta_{m}^{*}$ and $\eta_{r} \leq \eta_{r}^{*}$.

First, from Figures 6-7, one can find that the profits of the retailer and the supply chain decrease with $\eta_{r}$ but that of the manufacturer increases in the region where both firms have positive profits. However, Figures 8-9 show the inverse result.

The above observation is also to say that the profits of both the manufacturer and the retailer decrease with their own altruistic preference, but increase with the other's preference. That is,

$$
\partial \pi_{i} / \partial \eta_{i}<0, \partial \pi_{i} / \partial \eta_{i}>0, i, j \in\{m, r\}, i \neq j .
$$

Moreover, the profit of the supply chain decreases with $\eta_{r}$ and increases with $\eta_{m}$, i.e.,

$$
\partial \pi_{s} / \partial \eta_{r}<0, \partial \pi_{s} / \partial \eta_{m}>0
$$

This implies that with change of the altruistic preferences, the retailer's and the chain's profits change in the same direction, while the manufacturer's profit changes in the reverse direction.

By classifying the members as egoistic liability (when his/her altruistic preference is low, henceforth, E) or altruistic liability (when his/her altruistic preference is high, henceforth, A), we divide supply chains into the following four types where $\mathrm{M}$ and $\mathrm{R}$ represents the manufacturer and the retailer, respectively.

\begin{tabular}{cc} 
AA & AE \\
(Altruistic M, Altruistic R) & (Altruistic M, Egoistic R) \\
EA & EE \\
(Egoistic M, Altruistic R) & (Egoistic M, Egoistic R) \\
\hline
\end{tabular}

For example, type AA represents supply chains where both the manufacturer and the retailer have altruistic liabilities, and Type AE represents supply chains where the manufacturer has altruistic liability but the retailer has egoistic liability. Then, we get the following observation for comparing the four types from the monotone properties of the profits discussed above.

Observation 2 The supply chain with Type AE is the best for both the system and the retailer, while the supply chain with Type EA is the best for the manufacturer.

It is intuitive that either the manufacturer or the retailer may be damaged from being too altruistic, if his/her partner is too selfish. But it is interesting to discover that 
the chain will be damaged from an altruistic retailer but benefited from an altruistic manufacturer.

We further observe from Figures 6-9 that in compareson to $\eta_{m}$, the effect of $\eta_{r}$ on $\pi_{m}$ and $\pi_{r}$ is more serious but the effect on $\pi_{s}$ is less serious. In a word, the profits of both firms change with $\eta_{r}$ more sharply than with $\eta_{m}$; while $\pi_{s}$ increases more sharply with $\eta_{m}$. Especially, when the manufacturer is not too altruistic, e.g., $\eta_{m} \leq 0.2$ when $\eta_{r}=0$ or $\eta_{m} \leq 0.2$ when $\eta_{r}=3 / 7$, the increase of $\eta_{m}$ would not reduce her own profit but increase both the retailer and the chain' profits. But if the retailer increases his altruistic preference a little, he has to suffer a significant loss and so does the chain. Thus, we have the following observation.

Observation 3 A manufacturer with altruistic liability will benefit both the supply chain and the retailer but would not hurt herself, while a retailer with altruistic liability will hurt both himself and the supply chain.

By summarizing the above discussions, we present the following proposition.

Proposition 5 In order to form a good supply chain with one manufacturer (as the leader) and one retailer (as the follower), a manufacturer should find an egoistic retailer, while a retailer should find a manufacturer who has altruistic liability.

One main insight of this paper is given in the proposition above. That is, the manufacturer, as the leader of the game, should be in charge of the supply chain. This implies that she should consider not only her own profit but also the retailer's profit, i.e., the profit of the whole supply chain. So, the manufacturer behaves like a government taking into consideration the total social utility of the nation. On the other hand, as the follower of the game, the retailer is always in a passive status, no matter what type he is. As mentioned previously, his decisions are significantly affected by not only his own type, but also the manufacturer's type. Therefore, the retailer should do his best work without taking the whole supply chain into consideration. That is, the retailer behaves like persons in a nation: believing that doing his best will benefit the total social utility of the nation, as explained by Smith's theory of the invisible hand in the market. The result given in Proposition 5 above may be used for partner selection for firms to form a good supply chain.

\section{Conclusions}

Based on a generalized newsvendor setting, we study the coexistence of competition and cooperation in a supply chain, where such issues as pricing, ordering, and advertising/sales effort are involved. Three types of supply chains, i.e., the integrated, decentralized, and coopetitive systems are investigated. In this paper, coopetition is modeled by introducing firms' altruistic preferences.
With this, each firm considers not only his own profit but also the partner's one when making decisions.

One of our important finds is that all the decisions and performance in the supply chain of the coopetitive scenario are between those of the other two scenarios. Another important find is that a supply chain will benefit when the manufacturer is altruistic, having concern for the total profit of the supply chain, and the retailer is egoistic, only having concern for himself. This find may benefit firms in finding a suitable partner to form a good supply chain (i.e., with larger profit).

However, we have not obtained enough analytical results on the effect of altruistic preferences on the firms' decisions and profits. This may be left for further research, though it may prove to be quite challenging. Another area for further research is to consider multiplicative demand. Finally, it is interesting to consider the altruistic preferences in other models for supply chain management.

\section{Acknowledgements}

We would like to thank Yusen Xia, seminar participants at the Fudan university for thoughtful comments. The project is supported in part by the National Natural Science Foundation of China through grant 71101092 and 70832002, Shanghai Leading Academic Discipline Project (Number B210, S30501), Doctoral Fund of Ministry of Education of China (20113120120012), and Shanghai Innovation Fund (11YS122).

\section{REFERENCES}

[1] T. H. Cui, J. S. Raju and Z. J. Zhang, "Fairness and Channel Coordination," Management Science, Vol. 53, No. 8, 2007, pp. 1303-1314. doi:10.1287/mnsc.1060.0697

[2] E. L. Porteus, "Foundations of Stochastic Inventory Theory," Stanford Business Books, Stanford, 2002.

[3] T. M. Whitin, "Inventory Control and Price Theory," Management Science, Vol. 2, No. 1, 1955, pp. 61-68. doi:10.1287/mnsc.2.1.61

[4] N. C. Petruzzi and M. Dada, "Pricing and the Newsvendor Problem: A Review with Extensions," Operations Research, Vol. 47, No. 2, 1999, pp. 183-194. doi:10.1287/opre.47.2.183

[5] V. Agrawal and S. Seshadri, "Impact of Uncertainty and Risk Aversion on Price and Order Quantity in the Newsvendor Problem," Manufacturing \& Service Operations Management, Vol. 2, No. 4, 2000, pp. 410-423. doi:10.1287/msom.2.4.410.12339

[6] F. Y. Chen, H. M. Yan and L. Yao, "A Newsvendor Pricing Game," IEEE Transactions on Systems, Man, And Cybernetics - Part A: Systems and Humans, Vol. 34, No. 4, 2004, pp. 450-456. doi:10.1109/TSMCA.2004.826290

[7] Y. Gerchak and M. Parlar, "A Single Period Inventory Problem with Partially Controllable Demand," Computers 
and Operations Research, Vol. 14, 1987, pp. 1-9. doi:10.1016/0305-0548(87)90052-9

[8] M. Khouja and S. S. Robbins, "Linking Advertising and Quantity Decisions in the Single-Period Inventory Model," International Journal of Production Economics, Vol. 86, No. 2, 2003, pp. 93-105. doi:10.1016/S0925-5273(03)00008-2

[9] A. Krishnamoorthy, A. Prasad and S. P. Sethi, "Optimal Pricing and Advertising in a Durable-Good Duopoly," European Journal of Operational Research, Vol. 200, No. 2, 2010, pp. 486-497. doi:10.1016/j.ejor.2009.01.003

[10] S. R. Chandukala, Y. D. Edwards and G. M. Allenby, "Identifying Unmet Demand," Marketing Science, Vol. 30, No. 1, 2011, pp. 61-73. doi:10.1287/mksc. 1100.0589

[11] M. Lariviere and E. Porteus, "Selling to the Newsvendor: An Analysis of Price-Only Contracts," Manufacturing and Service Operations Management, Vol. 3, No. 4, 2001, pp. 293-305. doi:10.1287/msom.3.4.293.9971

[12] G. P. Cachon, "Supply Chain Coordination with Contracts," In: S. Graves and T. De Kok, Eds., Handbooks in Operations Research and Management Science: Supply Chain Management, North Holland, Amsterdam, 2003.

[13] F. Bernstein and A. Federgruen, "Decentralized Supply Chains with Competing Retailers under Demand Uncertainty," Management Science, Vol. 51, No. 1, 2005, pp. 18-29. doi:10.1287/mnsc. 1040.0218

[14] C. A. Yano and S. M. Gilbert, "Coordinated Pricing and Production/Procurement Decisions: A Review," In: A. Chakravarty and J. Eliashberg, Eds., Managing Business Interfaces: Marketing, Engineering and Manufacturing Perspectives, Kluwer Academic Publishers, Boston, 2003.

[15] L. M. Chan S. Z. J. Max, D. Simchi-Levi and J. Swann, "Coordination of Pricing and Inventory Decisions: A Survey and Classification," In: D. Simchi-Levi, S. D. Wu and Z. J. Max Shen, Eds., Handbook of Quantitative Supply Chain Analysis: Modeling in the E-Business Era, Kluwer Academic Publishers, Boston, 2004.

[16] H. Krishnan, R. Kapuscinski and D. A. Butz, "Coordinating Contracts for Decentralized Supply Chains with Retailer Promotional Effort," Management Science, Vol. 50, No. 1, 2004, pp. 48-63. doi:10.1287/mnsc. 1030.0154

[17] T. A. Taylor, "Supply Chain Coordination under Channel Rebates with Sales Effort Effects," Management Science, Vol. 48, No. 8, 2002, pp. 992-1007. doi: $10.1287 / \mathrm{mnsc} .48 .8 .992 .168$

[18] T. A. Taylor, "Sale Timing in a Supply Chain: When to Sell to the Retailer," Manufacturing \& Service Operations Management, Vol. 8, No. 1, 2006, pp. 23-42. doi:10.1287/msom.1050.0089

[19] S. X. Li, Z. Huang, J. Zhu, Y. K. Patrick and P. Y. K. Chau, "Cooperative Advertising, Game Theory and Manufacturer-Retailer Supply Chains," Omega, International Journal of Management Science, Vol. 30, No. 5, 2002, pp. 347-357. doi:10.1016/S0305-0483(02)00051-8

[20] J. Yue, J. Austin, M. Wang and Z. Huang, "Coordination of Cooperative Advertising in a Two-Level Supply Chain When Manufacturer Offers Discount," European Journal of Operational Research, Vol. 168, No. 1, 2006, pp. 6585. doi:10.1016/j.ejor.2004.05.005

[21] M. Esmaeili and P. Zeephongsekul, "Seller-Buyer Models of Supply Chain Management with an Asymmetric Information Structure," International Journal of Production Economics, Vol. 123, No. 1, 2010, pp. 146-154. doi:10.1016/j.ijpe.2009.07.016

[22] Y. He, X. Zhao, L. Zhao and J. He, "Coordinating a Supply Chain with Effort and Price Dependent Stochastic Demand," Applied Mathematical Modelling, Vol. 33, No. 6, 2009, pp. 2777-2790. doi:10.1016/j.apm.2008.08.016

[23] S. Netessine and N. Rudi, "Centralized and Competitive Inventory Models with Demand Substitution," Operations Research, Vol. 51, No. 2, 2003, pp. 329-335. doi:10.1287/opre.51.2.329.12788

[24] M. Kotabe, X. Martin and H. Domoto, "Gaining from Vertical Partnerships: Knowledge Transfer, Relationship Duration, and Supplier Performance Improvement in the U.S. and Japanese Automotive Industries," Strategic Management Journal, Vol. 24, No. 4, 2003, pp. 293-316. doi:10.1002/smj.297

[25] G. P. Cachon, "Competitive Supply Chain Management," In: S. Tayur, M. Magazine and R. Ganeshan, Eds., Quantitative Models of Supply Chain Management, Kluwer Academic Publishers, Boston, 1999, pp. 111-146. doi:10.1007/978-1-4615-4949-9 5

[26] A. Ha, L. Li and S. M. Ng, "Price and Delivery Logistics Competition in a Supply Chain," Management Science, Vol. 49, No. 9, 2003, pp. 1139-1153. doi:10.1287/mnsc.49.9.1139.16567

[27] A. M. Brandenburger and B. J. Nalebuff, "Co-Opetition," Currency Doubleday, New York, 1996.

[28] R. Anupindi, Y. Bassok and E. Zemel, "A General Framework for the Study of Decentralized Distribution Systems," Manufacturing \& Service Operations Management, Vol. 3, No. 4, 2001, pp. 349-368. doi:10.1287/msom.3.4.349.9973

[29] O. P. Kallasvuo, J. Gary, H. Franz, et al., "Moments of Truth: Global Executives Talk about the Challenges That Shaped Them as Leaders," Harvard Business Review, Vol. 85, No. 1, 2007, pp. 15-25.

[30] D. Knoch, A. Pascual-Leone, K. Meyer, V. Treyer and E. Fehr, "Diminishing Reciprocal Fairness by Disrupting the Right Prefrontal Cortex," Science, Vol. 314, No. 5800, 2006, pp. 829-832. doi:10.1126/science.1129156

[31] Y. Bhattacharjee, "The Value of the Stick: Punishment Was a Driver of Altruism," Science, Vol. 312, No. 5781, 2006, p. 1727. doi:10.1126/science.312.5781.1727a http://www.sciencemag.org/cgi/content/full/312/5781/172 $7 \mathrm{a}$.

[32] J. Henrich, R. McElreath, A. Barr, J. Ensminger, C. Barrett, A. Bolyanatz, J. Cardenas, M. Gurven, E. Gwako, N. Henrich, C. Lesorogol, F. Marlowe, D. Tracer and J. Ziker, "Costly Punishment across Human Societies," Science, Vol. 312, No. 5781, 2006, pp. 1767-1770. 
doi:10.1126/science. 1127333

[33] A. Ugarte and S. Oren, "Coordination of Internal Supply Chains in Vertically Integrated High-Tech Manufacturing Organizations," International Journal of Production and Economics, Vol. 67, No. 3, 2000, pp. 235-252. doi:10.1016/S0925-5273(00)00022-0

[34] G. Charness and M. Rabin, "Understanding Social Preferences with Simple Tests," The Quarterly Journal of Economics, Vol. 117, No. 3, 2002, pp. 817-869. doi:10.1162/003355302760193904

[35] C. H. Loch and Y. Wu, "Social Preferences and Supply Chain Performance: An Experimental Study," Management Science, Vol. 54, No. 11, 2008, pp. 1835-1849. doi: $10.1287 / \mathrm{mnsc} .1080 .0910$

[36] M. Laeequddin, B. S. Sahay, V. Sahay and K. A. Waheed, "Measuring Trust in Supply Chain Partners' Relationships," Measuring Business Excellence. Vol. 14, No. 3, 2010, pp. 53-69. doi:10.1108/13683041011074218

[37] S. M. Disney and T. Hosoda, "Altruistic Behavior in a Two-Echelon Supply Chain with Unmatched Proportional Feedback Controllers," Journal International Journal of Intelligent Systems Technologies and Applications, Vol. 6, No. 3, 2009, pp. 269-286.

[38] M. Avriel, "Nonlinear Programming: Analysis and Methods," Prentice-Hall, Englewood Cliffs, 1976. 


\section{Appendix}

Proof of Proposition 1. Suppose $\tau<A$ and let $\tilde{q}=\gamma(p) a_{m}^{s} a_{r}^{t}+A$, then $q<\tilde{q}<D$. Due to Equation (2) and $F(x)=0$ for $x<A$, we have

$$
\begin{aligned}
& \pi_{r}\left(w, a_{m}, \tilde{q}, p, a_{r}\right) \\
& =p E \min \{\tilde{q}, D\}-\left(w+c_{r}\right) \tilde{q}-a_{r}=\left(p-w+c_{r}\right) \tilde{q}-a_{r} \\
& >\left(p-w+c_{r}\right) q-a_{r}=\pi_{r}\left(w, a_{m}, q, p, a_{r}\right)
\end{aligned}
$$

The similar result can be obtained about $\pi_{r}\left(a_{m}, q, p, a_{r}\right)$. Therefore, $q$ will increase at least to $\tilde{q}$ in the process of the profit maximization. This means that the optimal $\tau$ is larger than $A$. Similarly, one can get $\tau \leq B$. Therefore, $A \leq \tau \leq B$.

Proof of Proposition 2. For any given $w, \varphi_{w}(p)=0$ at $p=w+c_{r}$. Meantime, $\varphi_{w}(p) \geq 0$ for any given $p \in\left[w+c_{r}, \bar{p}\right)$. Due to the continuity of $\varphi_{w}(p)$, we conclude that there must be a price $p_{w_{*}}^{*}$ maximizing $\varphi_{w}(p)$. Moreover, $w+c_{r}<p_{w}^{*}<\bar{p}$, or $p_{w}^{*}=\bar{p}$.

Now we show the uniqueness of $p$. Let $y(p)=\left[p \gamma^{\prime}(p)+\gamma(p)\right] / \gamma^{\prime}(p)-c_{r}$. Because $y^{\prime}(p)=\left[2 \gamma^{\prime}(p)^{2}-\gamma(p) \gamma^{\prime \prime}(p)\right] / \gamma^{\prime}(p)^{2}>0$ where the inequality is resulted from Assumption 1, $y(p)$ is strict increasing in $p$. Thus $y$ and $p$ have a relationship of one-one correspondence. Thus, for any $y=w$, we have a unique $p_{w}$ such that $w=y\left(p_{w}\right)$, i.e.,

$\left(p_{w}-w-c_{r}\right) \gamma^{\prime}\left(p_{w}\right)+\gamma\left(p_{w}\right)=0$. Thus, the solution of $\varphi_{w}^{\prime}(p)=0$ is unique for each $w$.

Moreover, if $p_{w}^{*}<\bar{p}$ then $p_{w}^{*}$ must satisfy $\varphi_{w}^{\prime}(p)=0$. Hence, $p_{w}^{*}=p_{w}$ means that the maximizer of $\varphi_{w}(p)$ is unique.

Proof of Lemma 1. First, we assume that $p_{w}^{*}<\bar{p}$. $\kappa^{1} \varphi_{c_{m}}\left(p_{c_{m}}^{*}\right)^{(t+s) /(1-t-s)} \varphi_{c_{m}}^{\prime}\left(p_{c_{m}}^{*}\right)=0$ because $\varphi_{c_{m}}^{\prime}\left(p_{c_{m}}^{*}\right)=0$. Thus, due to Equation (10),

$$
M_{c_{m}}\left(p_{c_{m}}^{*}\right)=\int_{A}^{F^{-1}\left[\left(p_{c_{m}}^{*}-c_{m}-c_{r}\right) / p_{c_{m}}^{*}\right]} \bar{F}(\theta) \mathrm{d} \theta+A \geq 0
$$

By Proposition 2, $p_{c_{m}}^{*} \geq c_{m}+c_{r}$ and so $F^{-1}\left[\left(p_{c_{m}}^{*}-c_{m}-c_{r}\right) / p_{c_{m}}^{*}\right]$. Furthermore, $\bar{F}(\theta)$ is positive in a certain nonempty subset of $\left[A, F^{-1}\left[\left(p_{c_{m}}^{*}-c_{m}-c_{r}\right) / p_{c_{m}}^{*}\right]\right]$, and then $M_{c_{m}}\left(p_{c_{m}}^{*}\right)>0$.

From the proof of Proposition 2, we know that $p_{c_{m}}^{*}$, the maximizer of $\varphi_{c_{m}}\left(p_{c_{m}}\right)$, is unique. Therefore, $\varphi_{c_{m}}^{\prime}(p)>0$ in $\left[c_{m}+c_{r}, p_{c_{m}}^{*}\right)$ and $\varphi_{c_{m}}^{\prime}(p)<0$ in $\left[p_{c_{m}}^{*}, \bar{p}\right)$. Therefore, $M_{c_{m}}(p)>0$ for $p \in\left[c_{m}+c_{r}, p_{c_{m}}^{*}\right)$. In addition to $M_{c_{m}}\left(p_{c_{m}}^{*}\right)>0$ above, the inequality $M_{c_{m}}(p)>0$ holds in $p \in\left[c_{m}+c_{r}, p_{c_{m}}^{*}\right)$. Therefore, $\varphi_{c_{m}}^{\prime}(p)>0$ and $M_{c_{m}}(p)>0$ for any $p \in\left[c_{m}+c_{r}, \bar{p}\right)$ when $p_{c_{m}}^{*}=\bar{p}$.

The latter result is obvious. This completes the proof.
Proof of Theorem 2. The existence of optimal solutions is surely.

1) From Lemma 1 , we know $M_{c_{m}}\left(p_{c_{m}}^{*}\right)>0$. Due to $M_{c_{m}}\left(p_{c_{m}}^{* *}\right)<0$ and the differentiability of $M_{c_{m}}(p)>0$, there must be a price, denoted by $p^{I}$, in $\left(p_{c_{m}}^{*}, p_{c_{m}}^{* *}\right)$ which satisfies (11).

Let $a_{r}^{I}=a_{r}\left(p^{I}\right), a_{m}^{I}=a_{m}\left(p^{I}\right)$, and $q^{I}=q\left(p^{I}\right)$ (see Equation (9)). Due to $M_{c_{m}}\left(p^{I}\right)>0$ and Equation (9), $\left(p^{I}, q^{I}, a_{m}^{I}, a_{r}^{I}\right)$ satisfies the first-order condition (8). In the following, we prove that it satisfies the second-order condition.

Because $a_{m} / a_{r}=s / t$ holds here, we get $U_{s}$ as followed,

$$
U_{s}=\left(p-c_{m}-c_{r}\right) q-p \int_{A}^{\tau} F(\theta) \mathrm{d} \theta-a_{r}(s+t) / t
$$

where $\tau=q-(s / t)^{s} \gamma(p) a_{r}^{t+s}$. Thus, $\left(p^{I}, q^{I}, a_{r}^{I}\right)$ satisfies the first-order condition:

$$
\left\{\begin{array}{l}
\partial U_{s} / \partial p=q+(s / t)^{s} p \gamma^{\prime}(p) a_{r}^{t+s} F(\tau)-\int_{A}^{\tau} F(\theta) \mathrm{d} \theta=0, \\
\partial U_{s} / \partial q=p \bar{F}(\tau)-c_{m}-c_{r}=0, \\
\partial U_{s} / \partial a_{r}=(s / t)^{s} p \gamma^{\prime}(p) a_{r}^{t+s-1} F(\tau)-(s+t) / t=0 .
\end{array}\right.
$$

By examination, one can prove that the Hessian matrix of $U_{s}$ is negatively definite at $\left(p^{I}, q^{I}, a_{r}^{I}\right)$. Therefore, $\left(p^{I}, q^{I}, a_{m}^{I}, a_{r}^{I}\right)$ satisfies the second-order condition and so is a local maximizer of (IS)

The latter result is obvious.

2) According to the previous proof, any interior optimal solution of (IS) must satisfy $M_{c_{m}}\left(p^{I}\right)=0$ and $M_{c_{m}}^{\prime}\left(p^{I}\right) \leq 0$. Then there is no interior optimal solution when $M_{c_{m}}\left(p_{c_{m}}^{* *}\right)>0$, and the optimal decisions should be in their boundaries.

$M_{c_{m}}\left(p_{c_{m}}^{* *}\right)>0$ implies that $M_{c_{m}}(p)>0$ for all finite $p$. Thus, any increase in $p$ will leads to an increase in the profit $I(p)$. Thus, $p^{I}=\bar{p}$ and thus $N(\bar{p})$ is the optimal solution of (IS).

3) When $M_{c_{m}}\left(p_{c_{m}}^{* *}\right)=0$, it is clear that $N\left(p_{c_{m}}^{* *}\right)$ satisfies the first-order condition (8). This together with (1) imply the result. This completes the proof.

Proof of Proposition 4. The proposition is obvious due to $M_{c_{m}}\left(c_{m}+c_{r}\right)$.

Proof of Theorem 4. Recall that the previous firstorder conditions (8) and (12) for (IS) and (CS), respecttively, we have a common or alike part as follows,

$$
\left\{\begin{array}{l}
\partial U_{s} / \partial p=q+p \gamma^{\prime}(p) a_{m}^{s} a_{r}^{t} F(\tau)-\int_{A}^{\tau} F(\theta) \mathrm{d} \theta=0 \\
\partial U_{s} / \partial q=p \bar{F}(\tau)-w-c_{r}+\eta_{r}\left(w-c_{m}\right)=0 \\
\partial U_{s} / \partial a_{r}=\operatorname{tp} \gamma(p) a_{m}^{s} a_{r}^{t-1} F(\tau)-1=0 .
\end{array}\right.
$$

Clearly, Equation (18) is a unification which holds for the two special cases: $w=c_{m}$ in (IS) and $\eta_{r}=1$ in 
(DS). The first two equations in Equation (18) are identical for (IS), (DS), and (CS).

Hence, we solve these two equations to obtain the same functions $p(q)$ and $a_{r}^{q}$, and denote $U(q)=\left(q, p(q), a_{r}(q)\right)$. Then,

$$
\mathrm{d} U(q) / \mathrm{d} q=p \bar{F}(\tau)-w-c_{r}+\eta_{r}\left(w-c_{m}\right),
$$

denoted by $G$.

So it suffices to study $G$. For any given $w$ and $a_{m}$ we have

$$
\begin{aligned}
\frac{\mathrm{d} G}{\mathrm{~d} q}= & -p f(\tau)+\left[\bar{F}(\tau)+p f(\tau) \gamma^{\prime}(p) a_{m}^{s} a_{r}^{t}\right] \frac{\mathrm{d} p}{\mathrm{~d} q} \\
& +\operatorname{tpf}(\tau) \gamma(p) a_{m}^{s} a_{r}^{t-1} \frac{\mathrm{d} a_{r}}{\mathrm{~d} q}
\end{aligned}
$$

where $\mathrm{d} p / \mathrm{d} q$ and $\mathrm{d} a_{r} / \mathrm{d} q$ are implicitly determined by Equation (18).

We will show that $\mathrm{d} G / \mathrm{d} q<0$ at $q=q^{D}$ by Defining the following denotations.

$$
\begin{gathered}
J=\left|\begin{array}{lll}
\frac{\partial^{2} \pi_{r}}{\partial q^{2}} & \frac{\partial^{2} \pi_{r}}{\partial q \partial p} & \frac{\partial^{2} \pi_{r}}{\partial q \partial a_{r}} \\
\frac{\partial^{2} \pi_{r}}{\partial p \partial q} & \frac{\partial^{2} \pi_{r}}{\partial p^{2}} & \frac{\partial^{2} \pi_{r}}{\partial p \partial a_{r}} \\
\frac{\partial^{2} \pi_{r}}{\partial a_{r} \partial q} & \frac{\partial^{2} \pi_{r}}{\partial a_{r} \partial p} & \frac{\partial^{2} \pi_{r}}{\partial a_{r}^{2}}
\end{array}\right|, \quad J P A R=\left|\begin{array}{ll}
\frac{\partial^{2} \pi_{r}}{\partial p^{2}} & \frac{\partial^{2} \pi_{r}}{\partial p \partial a_{r}} \\
\frac{\partial^{2} \pi_{r}}{\partial a_{r} \partial p} & \frac{\partial^{2} \pi_{r}}{\partial a_{r}^{2}}
\end{array}\right|, \\
P Q=\left|\begin{array}{ll}
\frac{\partial^{2} \pi_{r}}{\partial p \partial q} & \frac{\partial^{2} \pi_{r}}{\partial p \partial a_{r}} \\
\frac{\partial^{2} \pi_{r}}{\partial a_{r} \partial p} & \frac{\partial^{2} \pi_{r}}{\partial a_{r}^{2}}
\end{array}\right|, \quad A R Q=\left|\begin{array}{ll}
\frac{\partial^{2} \pi_{r}}{\partial p^{2}} & \frac{\partial^{2} \pi_{r}}{\partial p \partial q} \\
\frac{\partial^{2} \pi_{r}}{\partial a_{r} \partial p} & \frac{\partial^{2} \pi_{r}}{\partial a_{r} \partial q}
\end{array}\right| .
\end{gathered}
$$

Similar to the proof of Theorem 2, we get $J<0$ and $J P A R>0$.

By using the implicit function existence theorem, we get $\left.(\mathrm{d} p / \mathrm{d} q)\right|_{q=q^{D}}=-P Q / J P A R$ and

$\left.\left(\mathrm{d} a_{r} / \mathrm{d} q\right)\right|_{q=q^{D}} \stackrel{q=q^{D}}{=}-A R Q / J P A R$. Substituting them into (21), we have

$$
\begin{aligned}
\left.(\mathrm{d} G / \mathrm{d} q)\right|_{q=q^{D}} \\
=\left\{-p f(\tau) J P A R-\left[\bar{F}(\tau)+p f(\tau) \gamma^{\prime}\left(p^{D}\right) a_{m}^{s} a_{r}^{t}\right] P Q\right. \\
\left.-t p^{D} f(\tau) \gamma\left(p^{D}\right) a_{m}^{s} a_{r}^{t-1} A R Q\right\} / J P A R
\end{aligned}
$$

Noting that the right-hand side of the equation above is exactly $J / J P A R$, we have $\left.(\mathrm{d} G / \mathrm{d} q)\right|_{q=q^{D}}<0$ for any given $\left(w, a_{m}\right)$. In the same way, we can prove that $\left.(\mathrm{d} G / \mathrm{d} q)\right|_{q=q^{C}}<0$ and $\left.(\mathrm{d} G / \mathrm{d} q)\right|_{q=q^{I}}<0$.

Now, we prove $q^{D} \leq q^{C}$. Suppose the retailer in (CS) (with $\eta_{r}<1$ ) chooses $\left(p^{D}, q^{D}, a_{r}^{D}\right)$. Remember that $\left(p^{D}, q^{D}, a_{r}^{D}\right)$ satisfies $p \bar{F}(\tau)-w-c_{r}=0$. Then $G\left(q^{D}\right)=\eta_{r}\left(w-c_{m}\right)>0$. Recalling further that $G\left(q^{D}\right)$ is the marginal retailing utility in $q$, the retailer will adjust his $q$ to satisfy $G(q)=0$. The retailer will increase his order quantity until $G(q)=0$ because $\left.(\mathrm{d} G / \mathrm{d} q)\right|_{q=q^{D}}<0$. That is, $q^{D} \leq q^{C}$ due to $G\left(q^{C}\right)=0$ and $\left.(\mathrm{d} G / \mathrm{d} q)\right|_{q=q^{c}}<0$.

We can prove $q^{C} \leq q^{I}$ in the same way. This completes the proof. 